\title{
COMMUNICATIVE-ANALYTIC METHOD IN TEACHING ENGLISH TO ADULTS AT COMMERCIAL ENGLISH SCHOOLS AND CENTERS IN UKRAINE
}

\author{
Oleg Tarnopolsky*
}

\author{
Golovposhtamt, abonentska skrynka 856, Dnipropetrovsk, 49000, Ukraine \\ Department of Applied Linguistics and Methods of Teaching Foreign Languages, \\ Alfred Nobel University, Dnipropetrovsk, Ukraine \\ Corresponding Email: otarnopolsky@mail.ru
}

\begin{abstract}
Keywords: learning English as the language of global communication, English language education for adults, commercial English language schools and centers, communicative-analytic approach to teaching and learning English
\end{abstract}

ABSTRACT. The growing use of English as the language of global communication leads to the growing demand for learning it among adult population of non-English-speaking countries. If such people did not have a chance of acquiring English during their school or university years but urgently need it for professional or personal purposes, they learn it in courses offered by numerous commercial language schools and centers. This article deals with the experience of teaching English at such schools and centers in Ukraine. The way of teaching and learning suggested in the article was developed to meet students' expectations and, at the same time, to be in full accordance with the most cutting edge achievements in today's approaches to organizing adult students' successful language acquisition. The developed method of teaching/learning was called the communicativeanalytic one since, on the one hand, it makes use of the best in communicative language learning required for optimal attainment of the final goal of language education for adults - developing their English communicative competence. On the other hand, the communicative approach is combined with learners' analysis, practicing, and consciousness-raising as to separate language forms that students believe to be indispensable for language acquisition. Experiential learning activities and cultural orientation of the method are discussed, as well as some peculiarities of using it in courses of different levels within a commercial English language program.

\section{INTRODUCTION}

The integration of the world today requires a single common language to be used in all cases of international intercourse - both personal and professional. Since the second half of the last century, English has become such a common language of not just international but of global intercourse 11] and that has enormously increased the demand for learning it. The absence of free command of English as the global medium of communication means great limitations for a person in their educational, professional, career, and even personal opportunities restricting such a person to living and functioning only inside one speech community, that of their own, without any chance of going beyond its narrow borders.

The tendency to ensure great numbers of people a good command of English for international intercourse has become very prominent in post-Communist countries, such as Ukraine, where hundreds of thousands of people are learning English for improving their life prospects. In that country not only children and teenagers but also adult people of almost all ages and from almost all strata of society are very active in their efforts to achieve English language proficiency sufficient for their personal or professional needs. But most adult people who are learning English now have already finished their secondary or even higher education. So, they are having their training in English at different commercial language schools or centers widely spread all over the 
country. Even high and higher schools students, if they are dissatisfied with the results of learning English at their secondary schools and universities, often resume or continue their English studies at commercial centers. A similar situation can be observed in a quite a few other countries. Though nobody has ever made a relevant statistical analysis, the English language education that is provided by commercial language schools or centers is typical for very many countries of the world. It concerns not only the English-speaking countries with commercial language schools and centers for foreigners. Great numbers of such schools function in Malta, Germany, Switzerland, Austria, the Netherlands, and many other European countries where English is not the national language.

It is clear that if commercial English language teaching and learning is so spread and popular, this, quite specific, form of language education has to be sufficiently researched in language teaching/learning pedagogy and methodology. That is important not only for Ukraine and all post-Communist countries but also for quite a number of other countries in the world where, as it has already been mentioned, this form of English language training has been spread. Unfortunately, there has been practically no researching this particular form and this is a serious drawback because, if great numbers of language learners are embraced by such a form and if it involves great numbers of teachers, it certainly must be thoroughly researched. Such research is needed for taking full account of its teaching/learning peculiarities with the purpose of developing specific but optimal organizational patterns, methods of teaching, ways of formulating the teaching goals, and of selecting learning contents.

With the aim of compensating for the drawback indicated above, we have been conducting (for longer than 20 years already) research into the commercial form of English teaching and learning in Ukraine. The research has been done and is still being done at The Commercial Foreign Language Center functioning on the premises and under the aegis of Alfred Nobel University, Dnipropetrovsk, Ukraine. That Commercial Foreign Language Center (further called Center) has been operating for longer than 23 years (since 1993), and that has given us an opportunity of collecting and analyzing quite a lot of research materials connected with commercial foreign language education.

The aim of this article is discussing and analyzing one important (if not the most important) aspect of the commercial system of English language teaching and learning developed by us at the Center. That aspect is the method of teaching elaborated for the specific conditions of commercial English language education. The particular method created by us was called the communicativeanalytic one because it organically combines the peculiarities of communicative and culturallyoriented language learning with analysis and practicing of separate language forms. That is done with the purpose of students' consciousness-raising [2] as to those forms to make using them in communication psychologically easier for adult learners. Everything concerning the method is considered further in the article.

\section{INTERVIEWING STUDENTS FOR DETERMINING THEIR NEEDS, REQUIREMENTS, AND ATTITUDES TO COMMERCIAL LANGUAGE COURSES}

Before our Center started functioning in 1993, in 1991/1992 we had been conducting broad interviewing of potential students in the city of Dnipropetrovsk (300 interviewees between 17 and 45 years of age: businesspeople, government employees, engineers, doctors, high and higher school students, industrial workers, researchers, and some others) [3]. The purpose of interviewing was clarifying potential learners' needs, requirements, and preferences for their future/potential English studies at the commercial Center. Such mass interviewing of potential students was repeated in 1996/1997 (225 interviewees of the same ages and occupational categories) [4]. After that last interviewing, only actually enrolled students were interviewed in the Center, and such current interviewing has been held every year since 1997 and until today using the same interviewing questions as in 1991/1992 and 1996/1997 interviews. Every year since $199860-70 \%$ of all the enrolled students are interviewed - counting in total not less than 100 persons in each consecutive academic year. 
It is on the basis of such "permanently running" interviews and learners' needs and requirements revealed in them that nine core courses have been developed for the English language program taught at the Center:

1. A short preparatory introductory course of English pronunciation for total beginners. The course is also designed for learners to develop the most elementary communicative skills, such as greeting, apologizing, thanking, introducing oneself, etc.

2. The beginner's/elementary course of oral communication in English for meeting the requirements of those who go abroad for a short period of time (for instance, tourism). The aim of the course is to achieve learners' level of English A1+/A2 according to the Council's of Europe Common European Framework of Reference for Languages [5].

3. The course of speaking, listening, reading, and writing in English on the pre-intermediate level with the aim of learners' achieving the level B1 according to the above-mentioned Common European Framework ... [5].

4. The course of speaking, listening, reading, and writing in English on the intermediate level with the aim of learners' achieving the level B1+/B2 [5].

5. The course of training for Cambridge international examination of English FCE/English First (speaking, listening, reading, and writing) - the upper-intermediate level, or level B2+ [5].

6. The course of training for Cambridge international examination of English CAE/English Advanced (speaking, listening, reading, and writing) - the advanced level, or level C1 [5].

7. The course of training for Cambridge international examination of English IELTS (speaking, listening, reading, and writing) - the advanced level, or level C1 [5].

8. The course of Business English (speaking, listening, reading, and writing) - the level from intermediate to advanced, from B2 to $\mathrm{C} 1$.

9. The course of English for Psychologists (speaking, listening, reading, and writing) - the level from intermediate to advanced, from $\mathrm{B} 2$ to $\mathrm{C} 1$.

Three questions in all the interviewing sessions since 1991/1992 always concerned students' attitudes to the methods of learning English. When formulating those questions, we had no doubt that all the students wanted to learn English for communication only - not for studying the language system as such. In the course of 23 years, our talks with both potential and enrolled learners at our Center have confirmed that conviction. However, how students believed it were best for them to acquire English for communicative purposes was a different question requiring clarification. So, on the basis of our confirmed conviction that students were learning the language for communication only, we formulated three interviewing questions to get a more or less clear answer how they wanted such learning to be implemented. The questions were: "How do you believe it is better to learn a foreign language - in communication only or by the way of focusing on language forms and practicing them?", "Are both approaches necessary in language learning and which of them should dominate, if any?", "What learning activities from the list that I have given you are the most attractive and interesting for you (the list included ten communicative learning activities, such as role plays, discussions, project work, etc., and ten examples of language-focused exercises)?" Besides the answers obtained to those three direct questions, even more materials as to students' attitudes, likes, and dislikes in what concerns the ways and methods of learning English were supplied by what learners were saying in the learning process itself and through observing them in that process.

Both from the answers to the questions above and from students' statements and observations in the teaching/learning process it became quite clear that learners, being interested in learning communication only, opted for the communicative approach to teaching and learning which they found the most attractive to them (96\% in 1991/1992 interviewing, 93\% in 1996/1997 interviewing, and from 94 to $97 \%$ in all the following years). Just the same could be said about the attractiveness for students of the communicative learning activities, such as, for instance, role plays (practically the same percentage of respondents).

Therefore, our primary direction in teaching adopted from the very beginning - developing students' communicative competence in English [6] by way of their learning communication in 
communication and through communication - was meeting students' own requirements, wishes, and expectations.

However, students" elaborations of their answers to the questions "How do you believe it is better to learn a foreign language - in communication only or by the way of focusing on language forms and practicing them?", "Are both approaches necessary in language learning and which of them should dominate, if any?" were, to some degree, in contradiction with what was said above. Although the overwhelming majority of respondents (see the percentage figures above) affirm that they like and want to learn the language through communication and the communicative learning activities, at the same time they are absolutely confident that purely communicative learning is impossible. They believe (90\% of respondents in 1991/92 and 1996/97 interviewing periods and from 85 to $92 \%$ in the following years) that focusing on language forms is indispensible, that those forms must be explained in details and thoroughly trained, and all the more so the earlier the stage of learning is and the lower the students' level is. All the respondents (100\%) agree that both the communicative approach and the approach focused on language forms are required in teaching/learning English but they are sure that the former approach can be introduced only when learners have already acquired a substantial vocabulary and the majority of grammar forms $(88 \%$ of respondents in 1991/92 interviewing, $82 \%$ in 1996/97 interviewing, and from 79 to $85 \%$ of respondents in the following years).

Therefore, the majority of respondents are interested in and attracted by one thing (to acquire communication skills through communicative learning activities) but believe that for achieving their learning goals they must do a different thing (to practice language forms). That is why they are totally unprepared to accept learning with no focusing on language forms (see Krashen's approach [7]) or without practicing grammar separately (see Lewis's lexical approach [8]). And it is worthy of note that students persist in those attitudes even today, 23 years after our first interviewing in 1991/1992. In $201379 \%$ of respondents made statements to that effect, and in $2014-85 \%$.

The students' choice of methods of language teaching based on language form focusing is not really surprising. It is due to the fact that, in most cases, just such were the methods used for teaching them foreign languages in their previous language learning experience. So, they often have no idea of any other methods, and other approaches to teaching and learning seem impossible or inefficient to them.

In view of the above facts, it is clear that in the conditions under consideration we cannot start with purely communicative language learning which seems unacceptable to students at the very beginning of their language studies. We should start with focusing on language forms, gradually introducing communicating learning activities and negotiating with students the transition to them until they finally oust the language form-focused activities.

It is the approach long ago suggested by Nunan [9] and some other authors (like Green [10]). Following it, we have developed the so called communicative-analytic method to be the basic one for teaching at our Center.

\section{THE FIRST CHARACTERISTIC FEATURE OF THE COMMUNICATIVE- ANALYTIC METHOD: GRADUAL AND MEASURED INTRODUCTION OF COMMUNICATIVE LEARNING ACTIVITIES}

This first feature of the method made us design the first very short (two month-long) preparatory introductory course of English pronunciation for total beginners as mostly analytical in nature since it is focused on explaining and training English pronunciation patterns and some fundamental grammatical forms (e.g., the verbs "to be" and "to have", the imperative mood, etc.). But even in this course not less than a quarter of time in class is devoted to communicative learning activities aimed at students' acquiring some elementary communicative skills (see in the list of courses above). On the basis of just such activities, the teacher tries to show students how much 
faster and more efficiently they can achieve their goals (e.g., to start speaking English) in communication than in language form-focused exercises.

This allows designing the second course in the program - the beginner's/elementary course of oral communication in English - as the one in which communicative learning activities aimed at developing learners' skills of speaking and listening are fully balanced with language form-focused learning activities ( $50 \%$ by $50 \%$ ). Beginning with the pre-intermediate level course, communicative learning activities start to dominate in the learning process (three quarters of all class time), and from the intermediate course they occupy almost all of it.

That does not mean that in the courses on the intermediate and advanced levels of General English and in the ESP courses focusing learners' attention on language forms is totally excluded. That would be a bad choice in view of the ideas concerning foreign language teaching in the conditions of absence of target language communicative environment (see $[11,12,13])$. However in more advanced levels of language teaching and learning limited processing of language forms is organized not by way of explicitly explaining the rules concerning those forms and their intensive practicing but by way of using the so called consciousness-raising approach [2], i.e., by attracting learners' attention to some language forms with comparing them to some other forms of the same language (not the students' mother tongue) and with reinforcing them in communication.

How in practice this gradual transition to communication is implemented can be demonstrated using as examples several learning activities from the first two courses in the program.

In the preparatory introductory course of English pronunciation the exercises like the two ones given below dominate (three quarters of all the learning activities):

Listen and repeat after the recorded speaker:

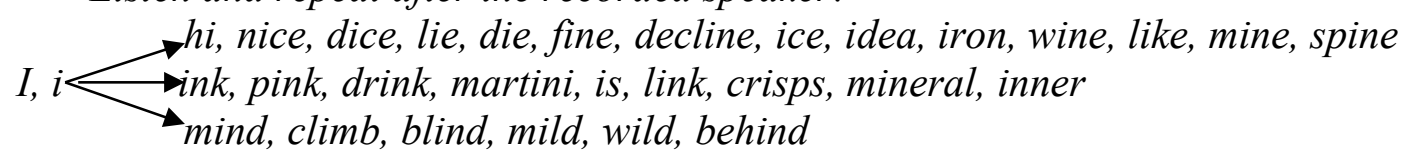

And now read these words aloud yourselves (without imitating the recorded version).

Complete the gaps with the correct form of the verb "to be":

It__ a room. I__ a doctor. These spoons__ long and those forks__ short, etc.

On the other hand, in the same preparatory introductory course one quarter of learning activities are either game-like or fully communicative, like the following ones:

Listen to the dialogue repeating after the speakers what they say. Then use the printed version of the dialogue to read it in pairs according to roles.

- Hello!

- Hi!

- I'm Sandra. What's your name?

- I'm Tony.

- Nice to meet you, Tony.

- Nice to meet you, too.

Practice the dialogue in "a chain." Who breaks "the chain," leaves the game.

- Hello!

- Hi!

-What's your name?

- I'm ...

-What's your name?

- I'm ...

- Nice to meet you.

- Nice to meet you, too.

And now, using the elements from the dialogue, introduce yourself to other students in the group. Each of the students is expected to meet every other student in the group. 
It is using the game or fully communicative learning activities like the ones above that the teacher negotiates with students their transition to communicative learning from language-formfocused one [9]. This is achieved by demonstrating how, after communicative learning, an immediate opportunity of taking part in some communication (however limited) emerges which never happens so quickly after doing language-form-focused exercises.

The effect of such negotiations, as our teaching experience shows, is such that in the following seven-month-long beginner's/elementary course of oral communication in English communicative learning can already occupy a no lesser place than language-form-focused one without making students psychologically uncomfortable. In this course, learners acquire the skills of speaking and listening in English, those skills being sufficient for solving autonomously all the communication problems that a person on a short visit abroad cannot avoid solving (like going through passport/customs procedures on arrival, checking in at a hotel, finding one's way in a city, eating out, shopping, etc.). The course is designed as a series of relevant dialogues-samples which, after studying and imitating, students start to dramatize $[14,15]$ in different ways - with numerous introductions of some changes into the original situations from sample dialogues. Thus, having passed through quite a number of dramatization activities relevant to each of the typical situations in the samples, they acquire the skills of communicating orally in various specific situations belonging to that type. For instance:

A. Dramatize all your contacts with a waiter (the partner in your pair) at a restaurant - from ordering your meal to paying at the end of it. The waiter will give you the menu-card.

$B$. Now do the same but the waiter will inform you that some entries in the menu-card you want to order cannot, in fact, be ordered because they have run out. You will need to make other choices or go to another restaurant,

C. The situation is the same as in A but when it is time to pay, you discover that you have either lost your wallet/left it in your hotel room or it has been stolen. What do you do and say?, etc.

Such communicative activities are alternated with explanations of new lexical and grammatical materials, which students first synthetically perceive, understand, and practice in sample dialogues and in the process of dramatizations, and later analyze through teacher's explanations and doing language-form-focused exercises. This is followed by returning again to new dramatizations but on a higher level of comprehension of the language material (synthesis analysis - higher level of synthesis). Language-form-focused exercises in this case are traditional ones, like in the preceding course (changing the tense of the verb in sentences, making interrogative and negative sentences, filling in the gaps in sentences with certain words, etc.). They are organized in such a way to meet students' expectations and their needs in language forms' analysis. But thanks to the fact that in the course under discussion such learning activities take no more than 50\% of class time while all the other time is devoted to communicative activities, students get fully used to the latter ones by the end of the course. As a result, a new change can be introduced in the next (pre-intermediate) course and the ones following it. It is the reduction of language-form-focused learning activities to one quarter of learning time or even less with allocating to communicative learning activities three quarters of the time or even more. Besides, as it has already been said, language-form-focused learning activities, beginning with the pre-intermediate course, change their nature into consciousness-raising ones [2,13] where language forms are not so much analyzed by the teacher with students practicing them in traditional exercises as students are made to pay their attention to such forms to become fully aware of them. Learners are encouraged to understand the meanings themselves by comparing new forms with the well-known ones and they are also encouraged to include subsequently those forms into their own communication.

There is one more essential change beginning with the pre-intermediate course. It is the gradual increase from course to course of the share of experiential learning activities among the growing numbers of communicative ones. But this makes the second characteristic feature of the communicative-analytic method and it will be discussed in the next section of the article. 


\section{THE SECOND CHARACTERISTIC FEATURE OF THE COMMUNICATIVE- ANALYTIC METHOD: INTRODUCING EXPERIENTIAL LEARNING ACTIVITIES BEGINNING WITH THE PRE-INTERMEDIATE COURSE}

As it is clear from what has been said above, the introduction of experiential learning activities $[16,17,18,19]$ occurs as soon as students become capable of participating in more or less sophisticated forms of communicative language learning, i.e. from the pre-intermediate course. Experiential learning activities in language teaching model extra-linguistic reality. They ensure that students experience their personal functioning in that modeled reality using the target language for such functioning. Thereby, communication skills are subconsciously constructed by students themselves in the process of quasi-genuine experience and communication. This subconscious construction intensifies and facilitates acquisition thanks to the fact of its being subconscious and, therefore, practically effortless. Acquisition comes as the outcome of learners' experiencing direct participation in target language communication.

Experiential learning activities include:

1. Role playing in the target language;

2. Simulating professional situations in the target language (in ESP courses);

3. Brainstorming some problematic issue(s) in the target language;

4. Case studies concerning some problematic issues and done in the target language;

5. Discussions of some problematic issues conducted in the target language;

6. Students' presentations on some issues delivered in the target language;

7. Students' search for extra-linguistic information through target language sources (Internet, audio, audio-visual, and printed ones). That search is undertaken for finding some particular information required for doing some creative learning assignments;

8. Writing papers in the target language (like essays, reports, memos, articles, letters, etc.) on the basis of the information that students have discussed orally and found during their information search;

9. Project work (when students do learning projects using the target language for doing such projects).

Just these forms of communicative learning activities gradually become more and more used beginning from the intermediate level course and dominate among all the kinds of learning activities in ESP courses.

Some examples of experiential learning activities from different courses are given below.

1. Role play (the intermediate course). Act out a dialogue between an employer and a working person (mother or father) who is asking for a release time from work to attend to her/his children's needs at school. Please, keep in mind that 'the employer' is certainly unwilling to give 'the employee' some extra release time. S/he will listen to reason only if 'the employee' proves that such extra release time is absolutely necessary and that her/his work will not suffer because of it.

2. Simulation (the course of Business English).

\section{Student A}

You are a representative of a manufacturer. Discuss with the middleman (a wholesaler or retailer) the conditions of distributing your product. He/she will store it. But who will transport it? You would prefer it to be the middleman because you lack the means of transportation. If he/she agrees to undertake transportation, you are willing to lower the price he/she will pay you for the products.

\section{Student B}

You are a middleman (a wholesaler or retailer). Discuss with the representative of a manufacturer the conditions of distributing his/her product. You will store it. But who will transport it? You prefer it to be the responsibility of the manufacturer because you lack the means of transport. But you can solve the problem and find the means of transport if the manufacturer agrees to lower the price at which you will buy the product. 
You would like a $15 \%$ reduction if you transport the product. Discuss this with the manufacturer's representative.

3. Discussion (the course of training for Cambridge international examination of English FCE/English First). Discuss the environmental problem in your home town or city and suggest the ways of solving them.

4. Project work (the course of English for Psychologists). All through their ESP course the students are compiling "A Short Psychological Encyclopedia" on the basis of everything they have done and learned, etc.

Communicative learning, and especially such its modification as experiential learning, is quite propitious for making the developed language program culturally-oriented, or intercultural. This makes the third feature of the suggested communicative-analytic method.

\section{THE THIRD CHARACTERISTIC FEATURE OF THE COMMUNICATIVE- ANALYTIC METHOD: CULTURAL ORIENTATION}

Adult students at commercial language schools and centers in Ukraine most often do not even suspect how culturally different communication is in different speech communities and how important the realization of that difference is for achieving communicative success [20,21]. But this is very well realized in the modern theory of language education that places sociolinguistic competence [5] factually at the head of all the components of communicative competence that foreign language learners must develop. It is also recognized that the culture to be taught to such learners should not be the culture with a big ' $C$ ' (literature, art, laws, political systems, etc.) but the culture with a small ' $c$ ' - forms of behavior reflected in everyday communication and making it socially acceptable $[22,23,24]$. If just such culture is not taught, those who have learned their English at commercial language schools and centers will not be able to use it abroad effectively, however well they know it. They may adequately use English linguistically in communication but inadequately socio-culturally which will not infrequently lead to communicative failures. That is why time and place for teaching culture must be found in every commercial course, however short it is, since teaching culture is not less (if not more) important than teaching the language.

In this way, our communicative-analytic method has from the very beginning been structured as a culturally-oriented (intercultural) one; all the more so that the communicative approach, which is the principal foundation of our method, and the intercultural approach ideally match each other [25]. On the one hand, the communicative approach is responsible for the way of teaching the language (how to teach - in communication through communication and for communication). On the other hand, the intercultural approach is responsible for the content of teaching and learning (what to teach - culture of the target speech community). That leads to the perfect match between the two approaches - one requiring teaching the target culture and the other showing the way of teaching it in communication and through communication.

Following this, within the framework of the communicative-analytic method teaching culture occupies a very important place beginning with the very first preparatory introductory course in the program. Even as early as in that course, when some elementary communicative formulas are introduced, students' attention is focused on their cultural connotations (e.g., why in English only a highly optimistic answer is expected to the question "How are you?" and never a pessimistic one which is quite possible in learners' home culture). In the next beginner's/elementary course of oral communication in English, students learn how to use city transport, order meals at restaurants, shop, and do other everyday things culturally correctly in English-speaking countries (e.g., that you cannot wave your hands or shout to attract the attention of a waiter at a restaurant but are supposed to meet his/her eyes and then ask him/her to approach by saying "Excuse me"). With every next course the processed cultural phenomena become more and more specific until in ESP courses professional etiquette behavior is taken care of (e.g., by explaining students that in business negotiations if an American takes off his jacket and rolls up the sleeves of his shirt, it means that for 
him the preliminaries are over and he is ready to get down to business, while for a German it is an opposite sign indicating a desire to relax or even rest a little).

It should be noted that in the implementation of the cultural orientation in the courses within our English-language program a lot, as it is clear from the examples above, depends on teacher's explanations and analysis of culturally adequate forms of behavior of representatives of Englishspeaking nations. After such explanations, students practice those forms of behavior in their own communication in English. So, in this respect, the suggested method is also communicativeanalytic, both communication and analysis concerning culture and not the language only.

The communicative-analytic method analyzed above has a number of important advantages discussed below.

\section{DISCUSSION: THE ADVANTAGES OF THE COMMUNICATIVE-ANALYTIC METHOD}

Discussing the advantages of the developed communicative-analytic method and its potential for improving the teaching/learning process at commercial English language schools and centers, it should be stated that it is just this method that allows our Commercial Foreign Language Center (mentioned before in this article) to improve its teaching/learning process continuously making that process move ahead with the times.

First of all, it is psychologically beneficial for students to start with analytical/languageform-focused learning activities that they have been used to and then gradually and evolutionally move to more efficient and intensive communicative/experiential activities - without introducing the latter ones in a revolutionary manner, which would inevitably cause a kind of learners' psychological shock and tacit resistance.

Second, when developing and improving the teaching/learning process at the Center, it is just this method that has made us introduce computer technologies, like computer language learning programs, Internet search on sites in English, etc., into English courses offered to students. Now, beginning from the elementary course of oral communication in English, such technologies are used in all courses. Their introduction was stimulated by students' clearly expressed interest in learning English with computers, as well as the advances in this particular aspect of language teaching and learning [26] (see section 2 above on taking into account learners' needs, requirements, and attitudes to teaching and learning English).

Third, the cultural component of the method makes us constantly reinforce the cultural constituent in every course in the program (beginning with the most elementary first two courses) according to today's approaches to the importance of culture-oriented studies in language acquisition.

Fourth, the growing share of experiential learning activities in all courses of the program (beginning with the pre-intermediate one) not only makes the students' work more intensive and closer to extra-linguistic reality. It also makes such work constructivist [19], the one in which students themselves construct their own knowledge and communication skills through practicing such skills in communicative learning activities faithfully modeling extra-linguistic activities and communication. This greatly enhances learners' motivation which substantially improves learning outcomes.

All the positive features listed above make the suggested method very well adapted to teaching and learning English to adults at commercial language schools and centers.

\section{CONCLUSION}

The communicative-analytic method of teaching English to adults at commercial language schools and centers in Ukraine has been presented in this article. The developed method is characterized by four basic features:

1. Taking into account adult students' needs, requirements, and attitudes to teaching and learning English; 
2. Ensuring on this basis learners' gradual evolutionary transition from analytical/languageform-focused learning activities (as more customary and acceptable to them at the beginning of their English studies) to communicative learning activities that greatly predominate in the teaching/learning process as a whole (though not at its early stages);

3. Ensuring gradual transformation of more traditional communicative learning activities into experiential ones making the learning process constructivist where learners themselves construct their own knowledge and communication skills in communicative practice modeling extra-linguistic activities and communication.

4. Ensuring cultural orientation in students' English studies beginning with the first most elementary course and providing for the expansion of the cultural constituent in every following course.

The method was not developed all at once but gradually constructed until all the above characteristics became clearly manifested in it. As a result, when it has been put together and implemented in practice as a single entity discussed in this article and the foundation for all the English courses taught at the above-mentioned language Center, the situation with those courses radically changed for the better. Students and teachers became quite satisfied with the learning outcomes, students' attendance stabilized, and the teaching/learning process became mostly successful remaining successful and fully approved by the students and teachers for more than 15 years already.

This makes it possible to recommend the suggested method to be considered by organizers of commercial teaching of English to adults in different countries where the conditions are more or less similar to those of Ukraine.

\section{References}

[1] D. Graddol, English next. Why Global English May Mean the End of 'English as a Foreign Language', British Council, 2006.

[2] W.E. Rutherford, Second Language Grammar. Learning and Teaching, Longman, London and New York, 1987.

[3] O. Tarnopolsky, Teaching English Intensively in a Non-English Speaking Country: Theory, Practice, and Results, ERIC Document Reproduction Service No. ED 428 579, 1999.

[4] O. Tarnopolsky, Writing English as a foreign language: A report from Ukraine, Journal of Second Language Writing. 9, No. 3 (2000) 209-226.

[5] Council of Europe, Common European Framework of Reference for Languages: Learning, Teaching and Assessment, Strasbourg, 2001.

[6] C.B. Paulston, Linguistic and Communicative Competence: Topics in ESL, Multilingual Matters, Clevedon, 1992.

[7] S.D. Krashen, Principles and Practice in Second Language Acquisition, Prentice-Hall International (UK) Ltd, London, 1981.

[8] M. Lewis, Implementing the Lexical Approach: Putting Theory into Practice, Thomson Heinle, 2002.

[9] D. Nunan, The Learner Centred Curriculum: A Study in the Second Language Learning, Cambridge University Press, Cambridge, 1988.

[10] J.M. Green, Student attitudes toward communicative and non-communicative activities: Do enjoyment and effectiveness go together? The Modern Language Journal. 77 (1993) 1-10.

[11] C. Doughty, J. Williams (Eds.), Focus on Form in Classroom Second Language Acquisition, Cambridge University Press, Cambridge, 1998. 
[12] R. Ellis, Instructed Second Language Acquisition: Learning in the Classroom, Basil Blackwell, Oxford, 1990.

[13] S.S. Fotos, Integrating grammar instruction and communicative language use through grammar consciousness-raising tasks, TESOL Quarterly. 28, No.2 (1994) 323-351.

[14] A. Maley, A. Duff, Drama Techniques in Language Learning: A Resource Book of Communication Activities for Language Teachers (Cambridge Handbooks for Language Teachers), Cambridge University Press, Cambridge, 1983.

[15] F. Debyser, Dramatisation, simulation, jeux de rôles: changer d'estrade, Le Français dans le Monde. 123 (1976) 24-27.

[16] D.E Freeman, Y.S. Freeman, Between Worlds. Access to Second Language Acquisition, Heinemann, Portsmouth, NH, 1994.

[17] M. Jerald, R.C. Clark, Experiential Language Teaching Techniques. Out-of-Class Language Acquisition and Cultural Awareness Activities. Resource Handbook Number 3. Second revised edition, Prolingua Associates, Bratleboro, Vermont, 1994.

[18] D. Kolb, Experiential Learning: Experience as the Source of Learning and Development. Prentice Hall, Englewood Cliffs, NJ, 1984.

[19] O. Tarnopolsky, Constructivist Blended Learning Approach to Teaching English for Specific Purposes, Versita, London, 2012.

[20] C. Alptekin, Target-language culture in EFL materials, ELT Journal. 47 (1993) 136-143.

[21] M. Byram, Teaching and Assessing Intercultural Communicative Competence, Multilingual Matters, Clevedon, 1997.

[22] J. Corbett, 'Chewing the fat' is a cultural issue, IATEFL Issues. 148 (1999) 2-3.

[23] D. Killick, Culture and capability. Crossing the divide, IATEFL Issues. 148 (1999) 4-7.

[24] O. Tarnopolsky, Teaching etiquette communicative behavioral patterns to students of English as a foreign language, Atlantis. XXIII, 2 (2001) 105-117.

[25] O. Tarnopolsky, Experiential B.E. teaching/learning: A happy combination of Intercultural and Communicative Approaches, Business Issues. 78 (2011) 7-8.

[26] M. Warschauer, A developmental perspective on technology in language education, TESOL Quarterly. 36, 3 (2002) 458-474. 